\title{
Hypertensive Emergencies in the Ambulance: Characteristics, Clinical Presentations and Complications - A Prospective Cohort Study
}

This article was published in the following Dove Press journal: Open Access Emergency Medicine

\author{
Dalal Alhasan' \\ Ameen Yaseen ${ }^{2}$ \\ 'Department of Applied Medical \\ Sciences, College of Health Sciences, \\ Public Authority of Applied Education \\ and Training, Kuwait, Kuwait; ${ }^{2}$ Audit \\ Department, Emergency Medical \\ Services, Ministry of Health, Kuwait, \\ Kuwait
}

Background: The objective of this study is to describe the characteristics of hypertensive emergencies in Kuwait aiming to provide a preliminary background to update the current guidelines and improve patients' management.

Methods: This is a prospective analysis of hypertensive emergency cases retrieved from emergency medical services (EMS) archived data between 1 January - 30 June 2020. Collected variables included patient characteristics, clinical presentations, vital signs, interventions, and complications. Outcome variable collected was: en route complications.

Results: Hypertensive emergency prevalence in Kuwait is 4.75 per 100,000. Most were nonKuwaiti (62\%) males (59\%) with a mean age of $57 \pm 14$ years. Most hypertensive emergency cases occurred at home (62\%). The hypertensive emergency BP threshold was; SBP 182 $(\mathrm{SD}=31)$ and diastolic BP (DBP) $108(\mathrm{SD}=18) .36 \%$ of hypertensive emergency cases had silent hypertension. $67 \%$ of hypertensive emergencies were verified using ambulance verification tools. Nitroglycerin was administered to only hypertensive emergencies suspected to have acute coronary syndrome or acute heart failure (50\%). Complications were seen in 9.5\% of hypertensive emergency cases.

Conclusion: Hypertensive emergency is rare in the ambulance but can progress into a serious situation. One in every 10 hypertensive emergency cases will require en route resuscitation. Hypertensive emergencies should be recognized and managed within their clinical context. The most common clinical presentation of hypertensive emergency is cardiac chest pain. Some pre-hospital verification tools confirm acute HMOD. Further research is required to establish hypertension emergency recognition and management guidelines in the prehospital setting.

Keywords: hypertensive emergency, emergency medical services, Kuwait, complications

\section{Introduction}

Hypertension is a worldwide health problem with a prevalence of $13-41 \%$ in 182 countries. ${ }^{1}$ It remains the leading cause of global mortality, with 10.4 million deaths every year. ${ }^{2}$ Hypertension is also known to be a silent disease ${ }^{2}$ with the aptitude to cause hypertension mediated organ damage (HMOD). ${ }^{3}$ This explains why HMOD can be the first sign of hypertension in some cases. ${ }^{4}$ When the severe elevation of blood pressure (BP) and acute HMOD occurs, life-threatening emergency results. ${ }^{4}$

In 1996, the Joint National Committee on Prevention, Detection, Evaluation, and Treatment of High Blood Pressure marked hypertensive emergency occurrence with BP threshold $>180 / 120$ mmHg. ${ }^{5}$ The committee also identified hypertensive
Emergency Medical Services, Applied

Medical Sciences Department, College of Health Sciences, Public Authority of Applied Education and Training, Kuwait Tel +965 97964699

Email dm.alhasan@paaet.edu.kw 
emergency clinical presentations to be mainly determined by the organ(s) acutely affected. ${ }^{5}$ However more recently, the international society of hypertension defined hypertensive emergency BP threshold $>180 / 110 .^{6}$ And symptoms suggestive of acute HMOD as; neurological deficit, chest pain, dyspnea, palpitation, loss of consciousness, dizziness, and other unspecific presentations. ${ }^{6}$

This wide variety of clinical presentations during hypertensive emergency made its recognition and management very challenging, especially in the prehospital setting. ${ }^{7-10}$

In emergency medical service (EMS), hypertensive emergencies account for a substantial proportion of EMS calls, missions, and fatal situations. ${ }^{7,8}$ And with the absence of clear prehospital hypertensive emergency recognition and management guidelines, ${ }^{11}$ an urgent need is raising to explore prehospital hypertension emergency recognition and management within its clinical context. ${ }^{8}$

One way to do this is to establish the scale of the problem and explore the current practices of prehospital hypertension emergency recognition and management. The main objective of this study was to identify prehospital hypertensive emergency characteristics, clinical presentations, and complications in Kuwait.

\section{Method}

\section{Setting}

Kuwait has a centralized dispatch center for ambulance services. For emergency calls, A universal emergency number 1-1-2 with a centralized dispatch for police fire and EMS is used. If medical assistance is required, the call is forwarded to the EMS call taker who answers the call, confirm the address, and responds by activating the nearest ambulance. The dispatched ambulance is staffed with two emergency medical technicians (EMT) or one paramedic and one EMT. And similar to the North American resuscitation guidelines, EMTs provide basic life support and paramedics provide advanced life support. As for blood pressure measurement, an automated non-invasive blood pressure oscillometric method is used to establish $\mathrm{BP}$ reading at first contact and after 5-10 minutes of the initial assessment. Kuwait EMS hypertensive emergency management protocol emphasizes; positioning the patient at 60-90 degrees, maintaining the patient's airway, breathing, and circulation, and the decision for initiating antihypertensive treatment is based on the identified end-organ damaged. Only patients who are suspected to have an acute coronary syndrome or acute heart failure are administered sublingual nitroglycerin. The diagnosis of these two conditions is primarily based on clinical physical examination and 12-lead ECG. The national EMS protocol limits scene time to 10 minutes and the present national EMS response time is $9.3 \pm 5$ minutes. $^{12}$

\section{Design}

This was a prospective cohort of hypertensive emergency cases which was set to collect relevant data from the EMS registry between Jauary1st - June 30th, 2020. Composed variables were; patient characteristics, vital signs, EMS response time, and EMS management. The primary outcome was en route complications.

\section{Participants}

In this analysis, we included all adults presenting with severely elevated BP $(>180 / 110)$ during first contact assessment or 5-10 minutes assessments plus a new clinical complaint suggestive of end-organ damage. Clinical presentations suggestive of end-organ damage were; severe headache, chest pain, dyspnea, palpitation, loss of consciousness, visual disturbance, paresis, acute neurological deficit, dizziness, and abdominal pain. ${ }^{4}$ Furthermore, chest pain, dyspnea, palpitation were verified with 12 lead ECG to confirm the end-organ damage. While visual disturbance, paresis, acute neurological deficit were verified with Cincinnati prehospital stroke scale to confirm the end-organ damage.

\section{Data Collection/Measures}

All study variables were found in the EMS patient report form. Patient report forms (PRF) were completed by EMS personals on the scene and then kept in the audit department archive. A team of 4 members was formed to manually collect PRF forms with hypertensive emergency cases. The researcher then analyzed each PRF to collect; patient characteristics, presenting complaint, medical history, vital signs, response time, management, 12- lead ECG, Cincinnati prehospital stroke scale, and en route complications. En route complications are defined as any condition that requires resuscitative measures in the ambulance. This includes respiratory arrest, cardiac arrest, and airway compromise in the ambulance.

Patient report forms with blood pressure $>180 / 110$ at the first contact assessment or 5-10 minutes assessments and clinical complaint of severe headache, chest pain, dyspnea, palpitation, neurologic deficit, dizziness, loss of 
consciousness, and abdominal pain were included in the analysis. $^{4}$

In terms of vital signs, those documented by EMS personals immediately during the patient on scene assessment were entered. Management included: controlled oxygen therapy, sublingual nitroglycerin. Controlled oxygen therapy is administering a sufficient amount of oxygen to maintain SPO2 at least $94 \%{ }^{13}$ Sublingual nitroglycerin was is administered per indications; patient complaining of cardiac chest pain or cardiac asthma plus systolic BP (SBP) $>100 \mathrm{mmHg}$. And it was withheld from patients suggestive of acute neurological symptom or abdominal pain. ${ }^{4}$

We also used medical history to identify those who are known to be hypertensive, or not known to be hypertensive (silent hypertension). A patient who reported to be previously diagnosed by a physician with hypertension or under anti-hypertensive therapy was categorized as a known hypertensive patient. While patients who were not diagnosed by a physician with hypertension and had no related medical conditions that can cause secondary hypertension were reported as silent hypertension patients.

In terms of cardiovascular risk factors, the co-existence of diabetes mellites, smoking, obesity, ischemic heart disease, previous cerebrovascular accidents marked the patient to have multiple cardiovascular risk factors.

During this research, all data were retained secured in password locked computer files, and restrained access by the research investigator. Data were kept confidential at all times and sharing outside the research context was not permissible.

\section{Sample Size}

In this study, convenient sampling was used. All hypertensive emergency cases met the inclusion criteria, treated and transported by EMS during the study period were embraced.

\section{Data Analysis}

Descriptive analysis was performed using Excel and Statistical package for social sciences (IBM SPSS Version 23). Frequencies, percentages, means, and standard deviations were Descriptive statistics such as frequency, percentage, mean and SD were calculated to encapsulate patient's characteristics, presenting complaint, vital signs, management, and en route complications. Missing data were preserved missing.

\section{Ethical Considerations}

This research was conducted per the Declaration of Helsinki ethical principles and good clinical practice. The institutional review board of the Kuwait Ministry of Health approved this project on 20 December 2019 (No.1278). Informed consent was not sought from study participants because data were maintained anonymous at this project at all times.

\section{Results}

Among 221 prehospital hypertensive cases, 95 patients met hypertensive emergency inclusion criteria (Figure 1). Immediate en route complications were seen in $9.5 \%$ of hypertensive emergency cases (Table 1). And ambulance staff were able to verify $67 \%$ of clinical presentations suggestive of end-organ damage in the ambulance (Table 2).

In this project, Kuwait's hypertensive emergency prevalence was 4.75 per 100,000 . Whereas hypertensive emergency BP thresholds were; SBP $182(\mathrm{SD}=31)$ and diastolic BP (DBP) 108 (SD=18). Additionally, 36\% of participants were not known to have hypertension, silent hypertension (Table 2).

In terms of hypertension emergency logistics, third of hypertensive emergencies were transported from primary clinics (Table 2). And all hypertensive emergency cases were transported to the hospital.

\section{Discussion}

This study described hypertensive emergencies in Kuwait EMS, which have not been reported before. And although the hypertensive emergency prevalence was found to be low, it had serious complications. Approximately 1 in every 10 hypertensive emergency patients developed en route complications that required immediate resuscitation. EMS personals either secured hypertensive emergency patients' compromised airway, $6.3 \%$ or performed cardiopulmonary resuscitation, $3.2 \%$. To the best of the authors' knowledge, this is the first study to estimate prehospital hypertensive emergency complications. Understanding the utilized intervention to treat and transport hypertensive emergencies in the prehospital setting can serve in structuring hypertensive emergency prehospital guidelines.

In terms of hypertensive emergency clinical presentation, nearly half of the hypertensive emergency patients presented with cardiac chest pain. Similar studies showed conflicting results. Zamopaglione et al 1996 confirmed that 


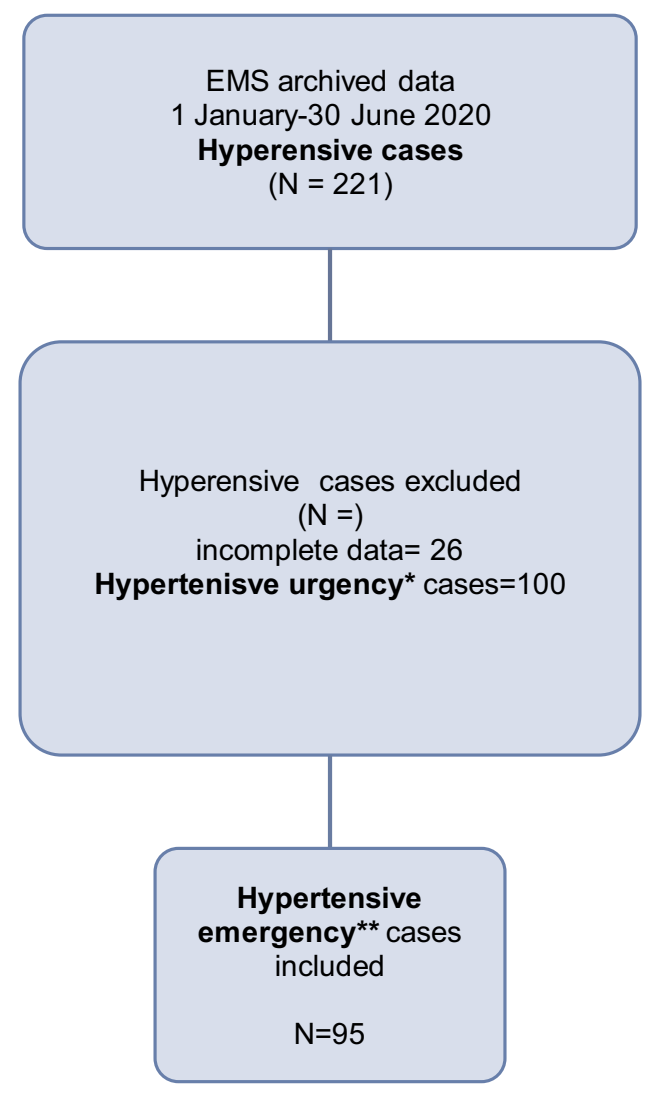

Figure I Selected study population flow chart.

chest pain is the most frequent clinical presentation of hypertensive emergency, ${ }^{4}$ others conveyed dyspnea as the commonest clinical presentation of hypertensive emergency. ${ }^{8,14-16}$ Grasping Hypertensive emergency clinical context is crucial for its recognition. Our result helped in clarifying hypertensive emergency clinical context.

Table I Hypertensive Emergencies Patients' Management and Complications

\begin{tabular}{|l|c|}
\hline \multicolumn{2}{|c|}{ Management } \\
\hline Position 60-90 degrees & $95(100)$ \\
\hline Controlled Oxygen therapy & $49(52)$ \\
\hline Nitroglycerin & $48(50)$ \\
\hline Response time (mean士std.) & $11 \pm 9.2$ \\
\hline En route complications* & $9(9.5)$ \\
Cardiac arrest & $3(3.2)$ \\
Respiratory arrest & $0(0)$ \\
Airway compromise & $6(6.3)$ \\
\hline
\end{tabular}

Note: $*$ En route complications complications $=$ all medical conditions that required immediate resuscitation on the ambulance such as cardiac arrest, respiratory arrest or airway compromise.

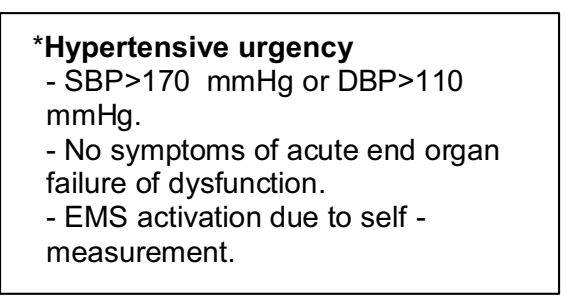

\section{$* *$ Hypertensive emergency} $\mathrm{SBP}>170 \mathrm{mmHg}$ or $\mathrm{DBP}>110$ $\mathrm{mmHg}$.

- EMS activation due to Symptoms

of acute end organ failure of dysfunction:

- Cardiac chest pain, dyspnea,

. Neurologic symptoms: severe headache, dizziness, visual disturbance, paresis.

. Abdominal pain.

This paper also underlined the use of prehospital hypertensive emergency verification tools. Other than Brockmann et al 2017, our study is one of few studies that report prehospital verification tools use. ${ }^{7} 67 \%$ of hypertensive emergency clinical presentations were verified on the ambulance using 12 lead ECGs and Cincinnati prehospital stroke scale. In which, 12 lead ECG confirmed that $55 \%$ of hypertensive emergencies led to the cardiac lesion and Cincinnati prehospital stroke scale verified that $11.5 \%$ of hypertensive emergencies led to the cerebrovascular incident. These results are different from the present literature, Martin et al 2004 retrospective study in the emergency department documented $58 \%$ of hypertensive emergencies corresponded to cerebrovascular accidents and $38 \%$ to the cardiovascular lesion. ${ }^{16}$ Again, with the absence of clear prehospital guidelines for a hypertensive emergency, our research serves in adding prehospital verification tools to confirm hypertensive emergencies.

Moreover hypertensive emergency recognition, acute HMOD was the first presentation in third of the hypertensive emergency patients. These findings are in line with current literature. $^{4,17}$ This should bring to EMS personals' attention 
Table 2 Hypertensive Emergencies Patients' Demographics, Vital Signs and Clinical Presentations

\begin{tabular}{|c|c|}
\hline Variables & $\begin{array}{l}\text { Hypertensive Emergencies } \\
\qquad \mathrm{N}=95(\%)\end{array}$ \\
\hline \multicolumn{2}{|c|}{ Demographics } \\
\hline $\begin{array}{l}\text { I. Gender } \\
\text { a.Male } \\
\text { b.Female }\end{array}$ & $\begin{array}{l}56(59) \\
39(4 I)\end{array}$ \\
\hline $\begin{array}{l}\text { 2.Nationality } \\
\text { a.Kuwaiti } \\
\text { b.Non Kuwaiti }\end{array}$ & $\begin{array}{l}36(37) \\
59(62)\end{array}$ \\
\hline Age (mean \pm std.) & $57 \pm 14$ \\
\hline $\begin{array}{l}\text { 3. Location } \\
\text { a. Home } \\
\text { b. Clinic } \\
\text { c. Public }\end{array}$ & $\begin{array}{c}59(62) \\
29(30.5) \\
7(7.5)\end{array}$ \\
\hline $\begin{array}{l}\text { 4. Cardiovascular risk factor } \\
\text { a.Hypertension } \\
\text { b.Silent hypertension } \\
\text { c.Multiple cardiovascular risk factors* }\end{array}$ & $\begin{array}{l}40(42) \\
35(36) \\
21(22)\end{array}$ \\
\hline \multicolumn{2}{|c|}{ Vital signs } \\
\hline $\begin{array}{l}\text { Pulse (beat per minute) } \\
\text { Oxygen saturation }(\%) \\
\text { Respiratory rate (breath per minute) } \\
\text { Systolic blood pressure }(\mathrm{mmHg}) \\
\text { Diastolic blood pressure }(\mathrm{mmHg})\end{array}$ & $\begin{array}{c}94 \pm 21.2 \\
97 \pm 2.5 \\
18 \pm 2.8 \\
182 \pm 31 \\
108 \pm 18\end{array}$ \\
\hline \multicolumn{2}{|c|}{ Clinical presentation } \\
\hline $\begin{array}{l}\text { Primary compliant } \\
\text { a. Cardiac chest pain } \\
\text { b. Dyspnea } \\
\text { c. Neurological deficit } \\
\text { d. Abdominal pain } \\
\text { e. Dizziness } \\
\text { f. Headache } \\
\text { g. LOC* } \\
\text { h. Palpitation }\end{array}$ & $\begin{array}{c}45(47.5) \\
5(5) \\
11(11.6) \\
3(3) \\
7(7.4) \\
19(20) \\
2(2) \\
3(3)\end{array}$ \\
\hline \multicolumn{2}{|c|}{ Confirmed end organ damage on the ambulance } \\
\hline $\begin{array}{l}\text { ACS using } 12 \text { lead-electrocardiogram } \\
\text { Acute stroke using Cincinnati prehospital } \\
\text { stroke scale }\end{array}$ & $\begin{array}{l}53(55) \\
1 I(I 1.5)\end{array}$ \\
\hline
\end{tabular}

Notes: Multiple cardiovascular risk factors= hypertension plus another cardiovascular risk factor such as; diabetes mellites, smoking, obesity, ischemic heart disease and, previous cerebrovascular accidents.

Abbreviation: LOC, loss of consciousness.

that patient's previous diagnosis with hypertension or not should not mislead EMS personals recognition of hypertensive emergency. Especially when dealing with a patient who has an elevated BP and a new presenting complaint.
More on hypertension emergency recognition, our results reported consistent SBP and DBP thresholds with the current international hypertension society guidelines. ${ }^{4}$ But was in slight difference with the seventh joint national committee of prevention, detection, evaluation, and treatment of high blood pressure BP thresholds. ${ }^{5}$

The ultimate prehospital management of hypertension emergency is founded on the acutely damaged organ. Our national EMS controlled oxygen therapy and antihypertensive therapy (nitroglycerin) practices were similar to other developed country EMS practices. ${ }^{18}$

In terms of hypertensive emergency characteristics, Hypertensive emergency age and gender prevalence were consistent with previous studies. Hypertensive emergencies were seen in males, mean age $57 \pm 14 . .^{19,20}$

Besides, $30 \%$ of hypertensive emergencies were transported from the primary clinic. Based on these findings the authors suggest initiating public hypertension preventive measures in primary clinics. Either through a national hypertension screen program in primary clinics ${ }^{21}$ or hypertension prevention campaign. ${ }^{22}$

In this study, we have established the prevalence of hypertensive emergencies in the ambulance. We also identified hypertensive emergencies frequent en route complications. Our research also adds to the conflicting evidence on hypertensive emergency clinical context and highlights the use of verification tools to confirm end-organ damage. These results highlight the need for further research to recognize and manage hypertensive emergency in the prehospital setting. At last, although $30 \%$ of Kuwait's population are hypertensive, this paper reports hypertensive emergencies for the first time in Kuwait. ${ }^{23}$

The results of this study should be viewed in the context of its limitation. First, omitted missing data from the analysis can result in reporting bias. Second, the study established acute HMOD based on prehospital data (PRF, 12 lead ECG, and Cincinnati prehospital scale). End organ damage was not confirmed from hospital records. This is because the national EMS registry is not linked to hospital registries. More studies are needed to determine hypertensive emergency outcomes. Third, medical history and medications were obtained from patient history and PRF. They were not cross-checked with hospital records, this can be a source of data bias. Lastly, the replication of this study in different settings may give different results. This research sample size is reflective of Kuwait's current population but not to other countries. The majority of countries in the globe have higher populations. ${ }^{24}$ 


\section{Conclusion}

Hypertensive emergency is rare in the ambulance but can progress into a serious situation. One in every 10 hypertensive emergency cases will require en route resuscitation. Hypertensive emergencies should be recognized and managed within their clinical context. The most common clinical presentation of hypertensive emergency is cardiac chest pain. Some pre-hospital verification tools confirm acute HMOD. Further research is required to establish hypertension emergency recognition and management guidelines in the prehospital setting.

\section{Abbreviation}

EMS, emergency medical services; BP, blood pressure; SBP, systolic blood pressure; DBP, diastolic blood pressure; HMOD, hypertension mediated organ damage.

\section{Data Sharing and Availability}

The dataset collected and analysed in this project are available from the corresponding author of reasonable request.

\section{Disclosure}

The authors declare that they have no competing interests in this work.

\section{References}

1. Zeng Z, Chen J, Xiao C, Chen W. A global view on prevalence of hypertension and human develop index. Ann Glob Health. 2020;86 (1):67. doi:10.5334/aogh.2591

2. Global Burden of Disease Risk Factor Collaborators. Global, regional, and national comparative risk assessment of 84 behavioural, environmental and occupational, and metabolic risks or clusters of risks for 195 countries and territories, 1990-2017: a systematic analysis for the Global Burden of Disease Study 2017. Lancet. 2018;392:1923-1994.

3. American heart association. Why High Blood Pressure is a "Silent Killer". American heart association; 2020. Available from: https:// www.heart.org/en/health-topics/high-blood-pressure/why-high-bloodpressure-is-a-silent-killer. Accessed February 11, 2020.

4. Zampaglione B, Pascale C, Marchisio C-P-P. Hypertensive urgencies and emergencies. Prevalence and clinical presentation. Hypertension. 1996;27(1):144-147. doi:10.1161/01.HYP.27.1.144

5. Bethesda. National High Blood Pressure Education Program. The Seventh Report of the Joint National Committee on Prevention, Detection, Evaluation, and Treatment of High Blood Pressure. United States: National Heart, Lung, and Blood Institute; 2004. Available from https://www.ncbi.nlm.nih.gov/books/NBK9629/. Accessed January 21, 2021.

6. Unger T, Borghi C, Charchar F, et al. 2020 international society of hypertension global hypertension practice guidelines. Hypertension. 2020;75:1334-1357. doi:10.1161/HYPERTENSIONAHA.120.15026
7. Brokmann J, Rossaint R, Müller M, et al. Blood pressure management and guideline adherence in hypertensive emergencies and urgencies: a comparison between telemedically supported and conventional out-of-hospital care. J Clin Hypertens. 2017;19:704-712. doi: $10.1111 /$ jch. 13026

8. Zoubeidi H, Boussema M, Karma S, Lammouchi L, Slaoui S, Boussema F. Need for prehospital management of hypertensive peaks. Arch Cardiovasc Dis Suppl. 2019;11(3):340. doi:10.1016/j. acvdsp.2019.05.022

9. Heller M, Duda J, Maha R, et al. Prehospital use of nifedipine for severe hypertension. Am J Emerg Med. 1990;8(4):282-284. doi:10.1016/0735-6757(90)90074-A

10. Alijotas-Reig J, Bove-Farre I, de Cabo-frances F, Angles-Coll R. Effectiveness and safety of prehospital urapidil for hypertensive emergencies. Am J Emerg Med. 2001;19(2):130-133. doi:10.1053/ ajem.2001.20008

11. Bakris G, Ali W, Parati G. ACC/AHA versus ESC/ESH on hypertension guidelines: JACC guideline comparison. $J$ Am Coll Cardiol. 2019;73(23):3018-3026. doi:10.1016/j.jacc.2019.03.507

12. Kuwait Emergency Medical Services 'Operation Department Annual Report'. Kuwait: Kuwait operation unit; 2013.

13. O’Driscoll B, Howard L, Earis J, Mak V. British thoracic society guideline for oxygen use in adults in healthcare and emergency settings. BMJ Open Respir Res. 2017;4(1):e000170. doi:10.1136/ bmjresp-2016-000170

14. Janke A, McNaughton C, Brody A, Welch R, Levy P. Trends in the incidence of hypertensive emergencies in US emergency departments from 2006 to 2013. J Am Heart Assoc. 2016;5(12):12. doi:10.1161/ JAHA.116.004511

15. Desta D, Wondafrash D, Tsadik A, et al. Prevalence of hypertensive emergency and associated factors among hospitalized patients with hypertensive crisis: a Retrospective Cross-Sectional Study. Integr Blood Press Control. 2020;13:95-102. doi:10.2147/IBPC.S265183

16. Martin J, Migashiama E, Garcia E, Lulzon M, Perto J. Hypertensive crisis profile.prevalence and clinical presentation. Arq Bras Cardiol. 2004;82(2):125-130.

17. Vilela-Martin JF, Van de Melo R, Kuniyoshi C, Abdo A. Yagertoledo hypertensive crisis: clinical-epidemiological profile. Hypertens Res. 2011;34(3):367-371. doi:10.1038/hr.2010.245

18. Hale K, Gavin C, O’Driscoll B. Audit of oxygen use in emergency ambulances and in a hospital emergency department. Emerg Med J. 2008;25(11):773-776. doi:10.1136/emj.2008.059287

19. Tomero E, Alonso S, Laguna P. Hypertensive crises at the hospital emergency services. The SUHCHRIHTA study. Emergencias. 2001;13:82-88.

20. Cerrilo M, Hernandez P, Pinilla C, Claros N, Otero M. Hypertensive crises: prevalence and clinical aspect. Rev Clin Esp. 2002;202:255-258. doi:10.1016/S0014-2565(02)71046-1

21. Jones D, Hall J. The national high blood pressure education program; thirty years and counting. Hypertension. 2020;39(5):941-942. doi:10.1161/01.HYP.0000018303.61360.28

22. Petrella R, Speechley M, Kleinstiver P, Ruddy T. Impact of a social marketing media campaign on public awareness of hypertension. Am J Hypertens. 2005;18(2):270-275. doi:10.1016/j.amjhyper.2004.09.012

23. World Health Organisation. Kuwait; Risk of Premature Deaths Due to Non-Communicable Diseases. World health organisation; 2016. Avilable from: https://www.who.int/nmh/countries/kwt_en.pdf?ua=1. Accessed December 20, 2020.

24. World Health Organisation. Global Health Observatory Data Repository. Switzerland: World Health Organisation; 2015. 


\section{Publish your work in this journal}

The Open Access Emergency Medicine is an international, peerreviewed, open access journal publishing original research, reports, editorials, reviews and commentaries on all aspects of emergency medicine. The manuscript management system is completely online

and includes a very quick and fair peer-review system, which is all easy to use. Visit http://www.dovepress.com/testimonials.php to read real quotes from published authors. 